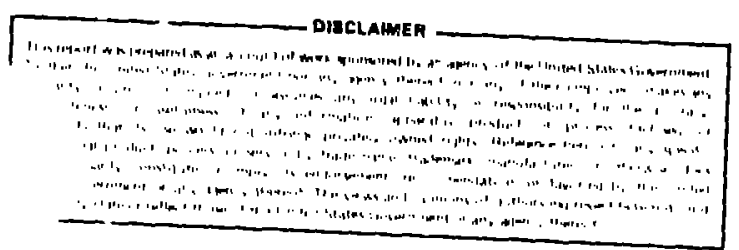

SUвMiт1. To: Workshop on. Sclence Underground Sept. 27 - Oct. 1, 1982 


\title{
A PROPOSED GEOLOGICAL SOLAR NEUTRINO MEASUREMENT
}

\author{
George A. Cowan and Wick C. Haxton \\ Los Alamos Nationai Laboratory, Los Alamos, NM 87544
}

\section{ABSTRACT}

It may be possible to measure the buron-8 solar neutrino flux, averaged over the past several million jears, frum the concentration of technetium -98 in molybdenum-rich ore. This geochemical experiment could provide the first test of nonstandard 50 lar models that suggest a relation between the chlorine-37 30lar neutrino puzzle and the most recent glacial epoch. The necessary conditions for achieving a meaningful measurement are identified and discussed.

\section{INTRODUCTION}

The standard solar modell postulates a complex set of thermonuciear reactions which evolve and change with time. The rate at which energy is generated is determined by conditions in the deep solar interior. Although there is considerable reason to believe that the model is generally correct, there is, unfortunately, almost no way to probe the solar interior to check its details.

A general solar model should comprehend processes leading to solar variability. Evidence for variability exists in the cycle of sunspot activity which appears to affect the terrestrial climate. This cycle is presently explained in terms of the dynamics of convection and rotation and does not call into question the det - is of energy production. However, long term changes have occurred in the terrestrial climate and, if these are due to solar variability. they imply possible changes in the rate of energy production which are not presently explained by the standard model.

Dranatic char.ges in climate hove occurred several times in terrestrial history when warm periuds of huridreds of million years duration have been interrupted by major glacial epochs which last a few million years. There is, as yet, no consensus that glacial epochs are related to energy changes in the sun. Such a relationship is hypothesized because the standard solar model can be modified to produce a cyclic change in solar temperature with a pattern corresponding to that of the glacial epochs. For example, the "solar spoon," proposed by Dilke and Gnughe ten years ago, postulates that the ratio $3 / l_{e} / \gamma_{H}$ varies sharply with radius when cqui- librium burning is achieved. This large concentration gradient induces large amiplitude, non-radid oscillations with a character- istic period of about i hour. Such oscillations produce a mixing of the core with colder material at ?arger radif. The approach to equilibrium prior to the onset of instability requires about 200 million years. The mixing is relalively sudden and the consequent core expansion prociuces a cooling trend with a $5 \%$ drop in solar luminosity for a period of about 3 million years. 
The last glacial epoch, the Pleistocene, began only three million years ago. If it were due to a solar instability, the core should presently be cooler than predicted by the standard model. Thus, this hypothesis can be used to help explain the solar neutrino anomaiy, i.e., the fact that the high energy neutrino component measured by the $37 \mathrm{Cl}-37$ Ar reaction is nearly a factor of four lower than the flux predicted by the standard model. The hypotinesis can be tested by measuring a product which is proportional to the high energy neutrino flux integrated over several million years.

The neutrino measurement being developed at Los Alamos involves the separation and analys is of $98 \mathrm{Tc}$, with a half-life of 4.2 million years, made by neutrino absorption in 98 Mo contained in a deeply buried ore deposit. An additional, potentially useful product is $97 \mathrm{Tc}$ with a half-life of 2.6 million years. A number of requirements inust be met in order to perform this measurement with usefui accuracy and at acceptable cost. These include:

1. Accurate neutrino capture cross sections must be available from theory and experiment.

2. A molybdenum ore deposit must exist in a working mine which is deep enough to reduce cosmic-ray-induced backgrounds to acceptable levels.

3. Backgrounds induced by naturally radioactive elements must be minor and measurable.

4. Separative and analvtical chemistry procedures must be developed to measure extremeily small quantities of $97 \mathrm{Tr}, 98 \mathrm{TC}$, and 99 Tr.

5. Geochemical immoblitity of Tc in the chosen ore body must be demonstrated.

These requirements are discuised in more detail in the following sections of this paper.

\section{NEUTRINO CAPTURE CROSS SECTIONS}

The threshold for the Mo ( $\nu$, ej $98 \mathrm{Tc}$ reaction is $1.68 \mathrm{MeV}$ but, because transitions from the $0^{+}$ground state of $98 \mathrm{Mo}$ to the $(6)^{+}$grouns state and $(4.5)^{+}$first excited state in $98 \mathrm{Tc}$ are strongly hincered, the effective threshold is $\gtrsim 1.74 \mathrm{MeV}$ and only high energy $8_{B}$ neutrinos contribute significantly.

The model-independent Ferint strength contribution to the formation of $98 \mathrm{TC}$ is negligibly weak. With sufficient accuracy for our present calculations, we estimate the model-dependent GT strangth distribution and calculate a production rate of 3.0 SNU (1SNU:10-36 captures per target atom per second) based on the standard solar model neutrino flux of Bahcall et al. 3 The GT transition can be napped experimentally with a typical accuracy of $s x$ based on measurement.s of forward angle $(p, n)$ reactions. 4 Such mescurements are planned for Mo and should be avallable relatively soc:n. 
From similar caiculations for the productions of $97 \mathrm{TC}$, we obtain a total production rate of 5.9 "equivalent" SNU, the result including a contribution from deexcitation by neutron emission in excited $98 \mathrm{ic}$.

\section{THE ORE DEPOSIT}

Although a number of unexploited Mo ore deposits may be known which are buried at a sufficient depth, the amount cf ore needed per sample is so great that we are limited by practical considerations to the use of working mines. We know of only one such active mine. It is located at the Henderson ore body at Red Mountein in Clear creek County, Coiorado. The ore averages approximately $0.5 \%$ molybdenite $\left(\mathrm{MoS}_{2}\right)$ and comes from a depth in excess of $1000 \mathrm{~m}$. The ore body extends to a depth $>1500 \mathrm{~m}$ below the surface ${ }^{5}$. At the time of ore body formation ( 25 million years ago) the depth of burial was $1500-1800 \mathrm{~m}$. The present minimum depth of overburden is due to glacial scouring which occurred about 10,000 years ago.

We caiculate that $1410 \mathrm{~m}$ of overburden at a density of 2.9 reduces the cosmic ray background to $10 \%$ of the solar neutrino signal.

\section{NATURAL RADIOACTIVITY BACKGROUNDS}

The most commor, Mo mineral at Henderson is molybdenite embedded in altered granitic rock. A representative sample contains $11.8 \mathrm{ppm}$ of uranium. The associated radioactivity is tive source of a number of potentially bothersome reactions which produce ${ }^{97} \mathrm{Tr}$. and $98 \mathrm{Tc}$. Direct $(\alpha, p)$ reactions are suppressed to negligible levels by high thresholds and Coulonb balriers. However $((x, p)$ reactions on $S$ followed by $(p, n)$ reactions on 97 Mo and $9 \mathcal{C}_{\text {Mo }}$ may be serious. If uranium is found ouly in the veinlets containing molybdenite crystals, the ratio of neutrino-induced to alphainduced $T C$ is given by $R=d \% / 3.75 U$ where $R$ is tine neutrinc capture rate in SNU, $U$ the uranfum content in $p p m$ and $\langle d=$ the mean thickness of molybdenite in micrometers. For $98 \mathrm{Tc}$, if $U$ is 11.8 and $\therefore d$ is 100 , the ratio is 11.3 . The result is inore favorable if the $U$ in concentrated in macroscopic yraills of host minerals which degrade the energy of the alpha particle.

Fission neutrons produce $(n, p)$ reactions on $S$ followed by $(p, n)$ reactior: on Mn. The sigiai-'n-background ratio is $610 R / U$ or about 216 .

Neutron capture on 96 Ru can make 97 rc to the extent chat $0.11 \mathrm{ppm}$ of $\mathrm{Ru}$ in the ore concentrate wlli generaie a ijo background. The $(\alpha, y)$ reaction on $93 \mathrm{Nb}$ generains a slinflar background level of $97 \mathrm{Tc}$ at a $\mathrm{Nb}$ content of a few ppm. We conclude that background levels of $97 \mathrm{Tc}$ may prove to be unacceptable. 


\section{SEPARATIVE CHEMISTRY AND ANALYSIS FOR TC}

'Ir calculations indicate that the untreated ore will contia in $5 \times 10^{4}$ toms of $99 \mathrm{Tc}$ per gram, the secular equilibrium level for mass 99 produced by the spontaneous fission of $238 \mathrm{U}$ at a concentration of $12 \mathrm{ppm}$. Neutrino-produced $97 \mathrm{TC}$ and $98 \mathrm{TC}$ concentrations shou d be a factor of 107 lower. When the molybdenite is concentrated from $0.5 \%$ to $90 \%$, the $23 \dot{8}_{\mathrm{U}}$ concentration should fall to $1.2 \mathrm{ppm}$ if all the $U$ is associated with minerals outside the molybdenite. A representative sample of concentrate actually contained $1 . \& \mathrm{ppm}$. Thus, the concentrate can be expected to contain $7 \times 10^{3}$ atoms of $99 \mathrm{TC}$ per gram and $10^{4}$ less $98 \mathrm{TC}$, the most troublesome mass number due to the ubiquity of Mo contamination. The concentrate froin 2600 tons of ore divided by the recovery efficiency will be required to produce such a sample. This represents considerably less than one day's production at the mine.

In the industrial process, the concentrate is roasted to produce molybdenum oxide at a controlled temperative of $70 \mathrm{C}^{\circ} \mathrm{C}$. An effluent yas stream, consisting largely of $\mathrm{SO}_{2}$ and excess air, is scrubbed with water to remove particles and volatile impurities before conversion of the $\mathrm{SO}_{2}$ to sulfuris acid. The scrub water, krow as the acid wash, should contain most of the environmentally objectionable element selenfum together with chemically similar rhenium and technetium. The selentum is precipitated as the suifide for environmental reasons. This precipitate will contain the Tc. We are developing separative techniques to recover traces of Tc from kilograms of selenium sulfide. The necessary chemistry is known, but the efficiency nust be determined.

\section{THE GEOCHEMICAL MOBILITY OF TC}

Based on measurements of loss rates of decay products of uranfum, particularly radiogenic lead, in a variety of urarium orrs, we are hopeful that ic loss rates will not excred 10-9 per ycar in the reducing sulfide-rich environment of the Heriderson ore. We intend to measure the degree to which ${ }^{99} \mathrm{TC}$ is in secular equiliorium with urantum. However, final reassurance on this question will rest on the meproducibility of results obtained from more than one location in the ore body.

1. J. N. Bahcall et a?., Phys. Rev. Lett. 40, 1351 (1978)

2. F. W. W. Dilke and D. 0. Gough, Nature, 540,262 (197\%)

3. J. N. Bahcall et al., Phys. Rev. Lett. 45, 945 (1980)

4. G. A. Gouldiing and C. C. Foster, private communication; C. D. Goodman et al.. Phys. Rev. lett. 44, 1755 (1980)

5. D. E. Rant et al.. in "Studies in Fteld Geology." R. C. Epis and R. J. Weimer, Eds. (Colo. School of Mines, Golden, 1976) p.477

6. G. A. Cowan and W. C. Haxton, Science, 216, 51-54 (1982)

7. G. A. Cowan and W. C. Haxton, los Alamos Srlence, 3, No.2, 46-56 (1982) 